\title{
LA INFLUENCIA FRANCESA EN EL ENTORNO DE MARÍA LUISA DE ORLEANS, 1679-1689: LOS COCINEROS DE LA REINA
}

\author{
Francisco José García PÉrez \\ Universitat de les Illes Balears-IEHM
}

\begin{abstract}
RESUmen. Uno de los objetivos prioritarios de este trabajo es el de mostrar la relación de la alta política con el servicio francés de las cocinas de la reina, intentando mostrar hasta qué punto fue importante para París y Madrid vigilar la influencia francesa alrededor de María Luisa de Orleans, lo que incluía, por supuesto, a sus propios cocineros. En este sentido, durante los diez años de María Luisa de Orleans como reina consorte, hubo una presencia francesa verdaderamente activa en la Corte de Madrid. Esta circunstancia afectó también a sus cocinas, donde hubo cocineros franceses entre 1679 y 1689. A lo largo de estas páginas, se presentará, además, un análisis de los cocineros que fueron sucediéndose, así como las circunstancias que rodearon sus nombramientos.
\end{abstract}

Palabras clave: María Luisa de Orleans, cocinero, Corte, París.

ABstract. One of the priority objectives of this work is to show the relationship of high politics with the French kitchen service, trying to show how important it was for Paris and Madrid to monitor the French influence around María Luisa de Orleans, which included, of course, to their own cookers. In this sense, during the ten years of María Luisa de Orleans as queen consort, there was a truly active French presence in the Court of Madrid. This circumstance also affected their kitchens, where there were French chefs between 1679 and 1689. Throughout these pages, an analysis of the cookers that were happening, as well as the circumstances of their appointments will be presented.

Keywords: María Luisa de Orleans, cook, Court, Paris.

Recibido: 17-8-2019 • Aceptado: 26-12-2019 • garcia.franj@hotmail.com 
EN LAS ÚLTIMAS DÉCADAS ha aumentado el número de estudios centrados en los oficios de Palacio. De hecho, contamos con numerosos trabajos que abundan en la Casa de la Reina y todos los departamentos que la componían (Simón Palmer, 1982; Simón Palmer, 1997a; García Barranco, 2002, pp. 95-107; Pérez Samper, 2014, pp. 337-370; Pérez Samper, 2011; Martínez Millán, 2016, pp. 307-333). Sin embargo, en lo que se refiere a los denominados «oficios de boca», que incluían al personal de las cocinas, todavía se observa un vacío historiográfico, que confiamos este trabajo contribuya a llenar.

\section{Sirviendo a la nueva reina: el monopolio de los cocineros franceses}

El 16 de julio de 1679, el Consejo de Estado volvía a tratar el asunto que llevaba poblando sus reuniones desde hacía ya meses: la boda del rey. Francia y España habían librado una larga guerra que duraba ya demasiado. Las negociaciones de paz, condicionadas por las voraces exigencias de Luis XIV y los desesperados intentos de los españoles para alcanzar unas condiciones respetables, no parecían llegar a buen puerto. Sin embargo, aquel verano, el tratado de Nimega era por fin una realidad. Y con aquella paz se sellaba también un contrato matrimonial. Carlos II iba a casarse con la princesa María Luisa de Orleans. El marqués de los Balbases había viajado a París para iniciar las negociaciones matrimoniales y ultimar todos los preparativos necesarios. Tras no pocas dificultades, y sabiendo lidiar hábilmente con el rey Cristianísimo, consiguió cumplir con su objetivo. De hecho, ese 16 de julio, los consejeros de Estado estaban debatiendo algunas cuestiones pendientes, entre las que se incluía el servicio que acompañaría a la nueva reina en su camino a España.

Aunque pueda parecer un asunto banal, los consejeros lo trataron muy detenidamente, sobre todo por la influencia que el servicio doméstico podía ejercer en aquella princesa. Por lo pronto, se consideró que María Luisa no mantendría entre sus damas a ninguna francesa, a excepción de algunas camaristas. Únicamente se creía oportuno que trajese «de hombres a su confesor, dos doctores, un cirujano, un barbero, estos serán franceses y un cocinero de boca $»^{1}$. Ese cocinero era Carlos Collard ${ }^{2}$. Desde el mismo momento en el que María Luisa partió del palacio de Fontainebleau, este se ocupó de servirla. Y como el trayecto desde París a Irún era largo, tuvo oportunidad de conocer sus gustos y platos favoritos, o por lo menos eso es lo que se deduce por lo que iba a ocurrir una vez que Collard fuese integrado en la Casa de la Reina.

Archivo Histórico Nacional (en adelante AHN), Estado, leg. 2796, s/f.

Los nombres de los cocineros franceses han sido traducidos al castellano porque así es como aparecen en la documentación de archivo consultada. 
Los consejeros contemplaban también la posibilidad de que pudiesen incorporarse más miembros del personal en el futuro: «se debe prevenir al marqués [de los Balbases] que, si Mademoiselle quisiere algunos criados más, no lo escasee, pues siempre se estará a tiempo acá de ejecutar lo que convenga, después de haber llegado»³. Aunque todo iba encaminado a contentar a la nueva reina, se vigilaron al detalle los inconvenientes típicos y más que probables que podían ocurrir. Para tal fin, se consultaron una y otra vez las dobles capitulaciones matrimoniales entre Isabel de Borbón y Felipe IV, por un lado, y Ana de Austria y Luis XIII, por el otro. A ellas se recurrió para buscar soluciones a posibles conflictos, como era, por ejemplo, la posibilidad de que María Luisa quisiera elegir a su camarera mayor, cargo que ya estaba reservado a la duquesa de Terranova. Por lo pronto, los consejeros eran optimistas y se habían contagiado de la alegría que embriagaba al propio Carlos II, deseoso como estaba de recibir a su bella esposa.

Con la proximidad de la llegada de María Luisa, se organizó la Casa de la Reina (Novo Zavallos, 2016, pp. 584-594). A lo largo de agosto y septiembre, el nuevo mayordomo mayor, el marqués de Astorga, y la duquesa de Terranova, en su condición de camarera mayor, hicieron los preparativos para la inminente salida de la Casa hacia Irún. Allí se reunirían con su señora. Pese a los problemas financieros por los que pasaba la Corona, no se ahorraron gastos para conseguir que todo estuviese a la altura de un acontecimiento como aquel. El condestable de Castilla, mayordomo mayor del rey, le informó de que «tiene resuelto que en esta Jornada del feliz casamiento de V.M. vayan sirviendo el mismo número de criados y oficios que fueron a la Jornada que S.M. — que Santa Gloria haya — hizo a Irún el año de $1660 »^{4}$. Para la formación de la Casa de la Reina, habían sido nombrados dos cocineros mayores. El primero era Juan Francisco Franco y llevaba algunos años sirviendo en Palacio. Por su matrimonio, había sido nombrado ayuda de cocina de Mariana de Austria en su condición de reina consorte (Pérez Samper, 2014, p. 347). Acompañó a la infanta María Teresa en su jornada para casarse con Luis XIV y, finalmente, había pasado a integrar el servicio que se inauguraba con la Casa de María Luisa de Orleans. El otro cocinero mayor era Francisco Vilón. Este había servido a la infanta Margarita desde que se convirtió en emperatriz del Sacro Imperio Romano, «hasta que por hallarse con mucha falta de salud le dio licencia el Señor Emperador para volverse a España como consta de las certificaciones que ha presentado $»^{5}$. Sirvió como ayuda de cocina de Carlos II en 1672, pues los puestos de cocinero mayor estaban todos ocupados, y solicitó pasar a

AHN, Estado, leg. 2796, s/f.

Archivo General de Palacio (en adelante AGP), Reinados, Carlos II, caja 99., ex. 1.

AGP, Personal, caja 1094, ex. 18. Expediente de Francisco Vilón, cocinero mayor de la reina. 
las cocinas de la regente Mariana de Austria. Tras el destierro de esta a Toledo, Vilón cocinó algún tiempo para la duquesa del Infantado (Simón Palmer, 1997a, p. 102). Cuando murió Juan José de Austria y doña Mariana regresó a Madrid, Francisco Vilón consiguió ser nombrado cocinero mayor a la espera de que llegase la reina consorte.

En septiembre todo estaba listo. A finales de mes, partió la Casa de la Reina hacia Irún. Una batería de carruajes, carros y carretas cruzaba las calles de la villa coronada y se dirigía al norte, en un trayecto fatigoso, largo y muy complejo. «Seguían los oficios de despensa, repostería, cocina y guardarropa, en treinta acémilas, con reposteros de tapicería de Flandes y Armas de S.E. cuidando de cada oficio los jefes ${ }^{6}{ }^{6}$ Los dos cocineros mayores españoles, es decir, Juan Francisco Franco y Francisco Vilón, formaban también parte de la comitiva, ya que se preveía que empezasen a servir a María Luisa desde el preciso momento en el que la Casa se reuniese con ella. Este encuentro entre la reina y todo el personal y miembros de su servicio implicaba ciertas repercusiones. Por ejemplo, estaba el hecho de que los criados franceses que acompañaban a la reina y los españoles que llegaban desde Madrid debían aprender a trabajar juntos. Como puede suponerse, no iban a faltar situaciones de tensión y enfrentamientos.

Mientras María Luisa de Orleans residía en el palacio que se le había preparado en Irún, se registraron algunas escenas que preludiarían lo que iba a ocurrir en el Real Alcázar algunos meses después. En primer lugar, las damas españolas observaban con recelo las licencias protocolarias que algunas camaristas francesas se tomaban con la reina, y «estos días se entraban hasta donde estaba la camarera mayor y se sentaban junto a ella y escudriñaban los trajes de España con notable atención y cuidado, tocando y manoseando todo cuanto había sin reservar cosa alguna» ${ }^{7}$. Solía ser común que la reina cenase rodeada de griterío y bailes, mientras se tocaban instrumentos y se cantaban canciones. Hasta tales niveles llegaba aquella situación «que no dejaban servir la vianda, recostándose sobre las mesas sin cortesía ni atención y todo se tolera deseando el hallar al Rey N. S. para lograr la ejecución de las etiquetas $»^{8}$. Se tuvo noticia de que también hubo peleas entre criados franceses y españoles, además de otros problemas en el servicio diario de la reina.

Estos recelos y disputas siguieron presentes en la Corte de Madrid. María Luisa de Orleans tuvo serios problemas para adaptarse a la etiqueta española (Lobato, 2007, p. 16). Aunque Carlos II hacía lo imposible por complacerla y se declaraba cada día más enamorado de ella, la nueva reina no olvidaba tan fácilmente sus días en París

Biblioteca Bartomeu March (en adelante BBM), Fondo Savo Millini, 39, s/f.

Biblioteca Nacional de España (en adelante BNE), ms. 7862, Relación de la jornada que se hizo desde el 26 de septiembre año de 1679 hasta el 24 de noviembre, y sucesos de las entregas de la Reina María Luisa de Orleans, f. 21.

$8 \quad$ BNE, ms. 7862, f. 34. 
(Maura, 1946, p. 119). Como decía el embajador veneciano, «continua altamente radicata in lei l'inclinazione alla corte [d]ov'è nata e non ha potuto per anco trasferire l'affetto in quella fatta propria dove regna» (Barozzi y Berchet, 1860, p. 481). Aprendiendo todavía el idioma, aquella joven de diecisiete años se aferraba a su círculo francés, algo bastante lógico si tenemos en cuenta que la camarera mayor era poco menos que un cancerbero que le negaba sus caprichos, y las damas escogidas para ella todavía se estaban adaptando a los cambios que traía su señora. De hecho, las impresiones del nuncio Savo Millini de que la consorte «si è lasciata soggettati dalla cameriera maggiore, dal Re e dalla Regina Madre $»^{9}$ eran solo ciertas en parte, porque María Luisa de Orleans se hallaba cada vez más hastiada con la presencia de su camarera mayor (Oliván Santaliestra, 2006, p. 404). Y mientras la duquesa de Terranova estrechaba el cerco sobre la nueva reina, esta se apoyaba en su pequeña camarilla (Borgognoni, 2019, p. 364). María Luisa disfrutaba pasando largo tiempo con la mujer del embajador francés, Madame Villars, y desfogaba sus frustraciones arropándose en su antigua nodriza, Nicole Françoise Quentin, conocida en la Corte como la Cantina (Echavarren, 2015, p. 129). Esto explica el hecho de que, pasados sus primeros meses en Madrid, María Luisa continuaba afanándose en mantener todo lo francés que había traído con ella, y eso, por supuesto, incluía a sus criados ${ }^{10}$.

Desde noviembre de 1679, las cocinas de la reina quedaron compuestas del siguiente modo: un despensero mayor, tres cocineros mayores, cinco ayudas, dos portadores, seis mozos de oficio, tres porteros, el busier, el aguador y el lechero. Entre todos ellos, había algunos franceses que permanecieron en Madrid tras la llegada de María Luisa a la Corte. Esteban Salvador Borrell «vino de Francia con la Reina Nuestra Señora y ejecuta las bebidas del gusto de S.M.» ${ }^{11}$. Entre los ayudas, estaban Nicolas Rigo y también Pedro Borre, que cumplía la función de confitero de la reina. Los nombres de los cocineros mayores ya los conocemos: eran los españoles Juan Francisco Franco y Francisco Vilón. El otro era el francés Carlos Collard.

Durante aquellos primeros meses en Madrid, los criados franceses habían sido automáticamente incorporados a la plantilla, pero trabajaban en las cocinas sin plaza fija ni gajes asignados. Y vista la importancia que tenían en el servicio de María Luisa, se hizo evidente la necesidad de modificar su situación. En efecto, en febrero de 1680, el mayordomo mayor de la reina, marqués de Astorga, escribió a Carlos II para tra-

BBM, Fondo Savo Millini, vol. 5/2, f. 12 v.

Isabel de Borbón también intentó mantener a su lado al personal francés que la acompañó a Madrid, incluyendo al cocinero Villaneuve. Fueron inevitables los enfrentamientos entre este y los cocineros españoles, especialmente por el monopolio del primero a la hora de realizar los platos de la reina. (Simón Palmer, 1997, p. 100).

11 AGP, Administración General, leg. 929, s/f. 
tar el asunto del personal francés de las cocinas. En cuanto a Pedro Borre, Astorga no dudó en aconsejar al rey «que al confitero que vino sirviendo a la Reina Nuestra Señora de Francia se le haga asiento como un ayuda y que goce con este título de los gajes, ración y casa de aposento» ${ }^{12}$. Es curioso el trastorno que provocó la presencia de un pastelero en el Real Alcázar, pues «no hay ejemplar de haber habido jamás en esta Real Casa ni en la del Rey N. S. este oficio de confitero mayor y será de grande inconveniente acrecentar oficios que nunca ha habido ${ }^{13}$. Por ese motivo, se mantuvo a Borre oficialmente como ayuda de cocina.

Más complicado de tratar todavía era el asunto del cocinero mayor Carlos Collard. Si Astorga podía justificar la permanencia del confitero por su habilidad a la hora de preparar los dulces y pasteles que tanto gustaban a la reina, era más difícil mantener en plantilla a Collard, pues ya había otros dos cocineros mayores con más años de experiencia sirviendo a la familia real. Finalmente, ese mismo mes de febrero, el mayordomo mayor terminó rindiéndose a la evidencia y remitió a Carlos II un memorial en el que le aconsejaba asignarle una plaza y gajes fijos, porque «antes bien parece que su instancia es justificada pues está sirviendo» ${ }^{14}$. De todos modos, se daba por hecho que Collard terminaría marchándose a París, como había ocurrido, por ejemplo, con algunos cocineros que llegaron con Isabel de Borbón (García Barranco, 2002, p. 104). Por eso era tan importante que, «si llega el caso de estar malo o volverse a Francia — como no dudo sucederá-, mandaré a los otros dos cocineros mayores asistan a verle obrar para que puedan ejecutar los platos que son del gusto de la Reina Nuestra Señora» ${ }^{15}$. Sin embargo, poco importaba que los cocineros españoles se esforzasen en aprender a cocinar al gusto de la nueva reina. María Luisa solo quería que Collard supervisase su menú diario.

Poco a poco, el personal francés empezó a hacerse con el control fáctico de las cocinas. Mientras el confitero Pedro Borre se ocupaba personalmente de la preparación de los dulces que se servían en las meriendas, Carlos Collard se convertía en imprescindible para la elaboración de las comidas de la soberana y únicamente se dejaba asistir por Nicolás Rigo. Pero a las tensiones que ya se vivían, fueron sumándose otras. Si los cocineros españoles tenían que ver impotentes cómo el francés monopolizaba la preparación de las viandas, llegó al Real Alcázar un nuevo cocinero francés. Se llamaba Lázaro Andrés y venía recomendado por el mismísimo padre de la reina (Simón Palmer, 1982, p. 35). Sabedor de que la adaptación de su hija a la Corte de

AGP, Personal, caja 16675, ex. 20, Expediente de Pedro Borre, confitero de la reina. AGP, Libros y Registros, registro 173, f. 173.

AGP, Personal, caja 16798, ex. 9. Expediente de Carlos Collard, cocinero mayor de la reina. Ibidem. 
Madrid no estaba siendo sencilla, el duque de Orleans «enviaba un gran cocinero de su gusto y satisfacción, y que este venía conducido y pagado hasta la frontera y que así me mandaba se diese forma de que en Irún se le socorriese y aviase en buena forma hasta aquí» ${ }^{16}$. Desde junio de 1680 , a Andrés se le hizo «merced de plaza de cocinero mayor de la Reina Nuestra Señora con todo el goce que por esta razón le pertenece» ${ }^{17}$. A partir de entonces, ambos tuvieron que aprender a colaborar, algo verdaderamente complicado si hacemos una visión retrospectiva.

Cada vez que los reyes programaban su traslado a alguno de los Sitios Reales, lo cual ocurría en diferentes épocas del año, siempre los acompañaban sus respectivas Casas. Aquellas jornadas a Aranjuez, El Escorial o el Pardo implicaban la movilización del personal palaciego necesario para cubrir todas sus necesidades diarias. Esta circunstancia afectaba, como no podía ser de otro modo, a los criados de las cocinas. El mayordomo mayor supervisaba personalmente la elección de aquellos que viajarían con la reina. Cuando Carlos II y María Luisa se trasladaron a Aranjuez en abril de 1681, el marqués de Astorga ordenó que los acompañasen los dos cocineros franceses, y esto lo sabemos porque junto a ellos iría «un cocinero mayor español» ${ }^{18}$. A estos se les sumaba, como no podía ser de otro modo, el confitero francés Pedro Borre. La presencia de Collard y Andrés no se cuestionaba, porque María Luisa así lo deseaba: «están sirviendo [escribía Astorga a Carlos II] únicamente porque S.M. la Reina Nuestra Señora tiene ordenado con gran precisión que no hagan sus viandas otros $»{ }^{19}$. Y, como era inevitable, ambos cocineros mayores empezaron a competir por el monopolio y el control de las cocinas de la reina.

En abril de 1681, se informó al mayordomo mayor de las disputas que frecuentemente originaban Collard y Andrés. Este segundo había acusado a su compañero de querer «ejercitar superioridad, quitándole los oficiales que le han de ayudar en la semana que le toca servir, y haciendo otras cosas muy perjudiciales» ${ }^{20}$. Al parecer, Collard no llevaba demasiado bien la llegada de Andrés, y menos aún que viniese recomendado por el duque de Orleans. Así que durante la semana que le tocaba trabajar, se ocupaba de extorsionar a los ayudas de las cocinas para que no ayudasen a Andrés. De hecho, ese mismo año se produjeron otros incidentes. Cuando se organizó la jornada anual a San Lorenzo de El Escorial en el mes de noviembre, Astorga volvió a ordenar a Collard y Andrés que se uniesen a la comitiva. Sin embargo, a última hora, se consideró que únicamente era suficiente la presencia de uno de los dos cocineros: «la causa de

AGP, Administración General, leg. 880, s/f.

AGP, Personal, caja 91, ex. 2. Expediente de Lázaro Andrés, cocinero mayor de la reina.

AGP, Administración General, leg. 781, s/f.

AGP, Administración General, leg. 929. s/f.

AGP, Administración General, leg. 880, s/f. 
no haber ido más de Carlos Colar fue porque por el cuarto de S.M. dijeron a V. Exa. bastaba Carlos Colar y así me lo insinuó V. Exa. para que lo ejecutase» ${ }^{21}$. A pesar de todo, Andrés, airado en su orgullo propio, exigía que se le diese la ración que se le había asignado para hacer la jornada, aun cuando estuviese excluido de ella. Como puede suponerse, sus demandas fueron denegadas, precisamente para evitar un precedente:

En cuanto a la ración que pretende por haber sido nombrado, se debe denegar por ser una pretensión sin ejemplar y que le habría para otros que, aunque han sido nombrados así en esta como en otras jornadas, no han ido a servir por haber caído enfermos, o por otra causa o accidente legítimo ${ }^{22}$.

A los conflictos entre ambos cocineros franceses, se les sumaba el desprecio que estos demostraban una y otra vez a los españoles. Porque Collard y Andrés, pese a la rivalidad que públicamente se profesaban, seguían negándose a trabajar con Franco y Vilón. En 1682, preparada ya la jornada a Aranjuez que tenía lugar antes de la llegada del verano, los franceses escribieron al marqués de Astorga pidiéndole que permitiese al ayuda de cocina Nicolás Rigo asistirles en Aranjuez, y que se le concediese la ración que se asignaba al servicio que iba a acompañar a los reyes. El contralor de la reina aconsejó al mayordomo mayor que «se debe denegar esta pretensión pues teniendo S.M. dos cocineros bastantes de quien no quieren valerse por ser españoles, no se han de acrecentar raciones cuando la despensa está cargada ${ }^{23}$. Todo esto explica el hecho de que, pasados los dos primeros años de la llegada de María Luisa de Orleans, toda la Corte mirase con recelo no solo a su círculo privado sino a todos los que componían el servicio francés. Por ello, cuando empezaron a plantearse reformas destinadas a ahorrar el excesivo gasto y saldar la montaña de deudas pendientes, se tuvo muy presente la cuestión de cuál iba a ser su destino.

\section{Medinaceli y las tensiones con Francia: los cocineros franceses en el punto de mira del Bureo}

Era tradicional en la dinastía de los Austrias que el rey y la reina hiciesen vida separada. El propio Alcázar de Madrid había sido diseñado de tal modo que las estancias de ambos estuviesen situadas en dos alas distintas de la residencia regia. Felipe IV había reforzado esta etiqueta, aislando a sus respectivas consortes a comer, a cenar y, en definitiva, a hacer vida diaria en sus aposentos privados. El mismo servicio de la

AGP, Personal, caja 91, ex. 2. Expediente de Lázaro Andrés, cocinero mayor de la reina.

Ibidem.

AGP, Personal, caja 880, ex. 29. Expediente de Nicolás Rigo, ayuda de cocina. 
vianda quedaba a cargo de las damas de la reina, que asumían sus respectivos oficios, como eran los de copera o trinchera (Simón Palmer, 1997b, p. 25). Para María Luisa se había establecido que le sirviesen «cada día diez y ocho platos, los diez a medio día y los ocho a la noche, $\sin$ [contar] los almuerzos y meriendas y sin las flamenquillas de regalo que se sirven a medio día $\rangle^{24}$. Su dieta privilegiaba los gustos franceses, algo que no sorprende demasiado, teniendo en cuenta la importancia que daba a que fuesen Collard y Andrés quienes elaborasen sus menús. Lo más común en su mesa eran los platos a base de carnes. Habitualmente primaba el consumo de aves, especialmente pollo, pichones y perdices, pero también paloma, calandria, alondra, codorniz y en ocasiones también pavo ${ }^{25}$. Además, se incluía ternera y cabrito, y «dos platos de pescados frescos en los días de pescado, cuando los hay según los tiempos» ${ }^{26}$. El consumo de pescado no era, ni de lejos, tan habitual en la Corte, primero por la dificultad de conducirlo hasta allí y también por el escaso valor nutritivo que los doctores de la época le atribuían. María Luisa prefería comer salmón, lenguado y a veces también atún, además de ostras ${ }^{27}$. La trucha no solía incluirse en sus menús, aunque se consideraba que «carece de mucho excremento y viscosidad, por lo cual no se desprecia» ${ }^{28}$.

En la mesa de la reina eran muy comunes los potajes, donde abundaban las verduras además de carnes y pescados. En cuanto al consumo de huevos, se aconsejaba que «sean frescos del día solo para sorbidos, y no duros ni fritos» ${ }^{29}$, lo que no quiere decir que se cumpliese a rajatabla. Contamos con algunos menús que pueden darnos una idea aproximada de los platos que se elaboraban en la mesa de los reyes: cocido de ave, dos pollos asados, albóndigas, lomo de ternera mechada, empanadillas de huevos y conservas, y pasteles de carne ${ }^{30}$. La marquesa de Villars, confidente de la reina mientras su esposo fue embajador en Madrid, constataba que «elle mange quatre fois le jour de la viande. [...] Il y a toujours à sa collation un chapon bouilli sur un potage, et un chapon rôti» (Gigault de Bellefonds de Villars, 1868, p. 110). En tiempos de Carlos y María Luisa fue muy típica también la preparación de empanadas, tanto calientes como frías, un plato que estaba ya muy popularizado en la Francia de Luis XIV

AGP, Personal, caja 91, ex. 2. Expediente de Lázaro Andrés, cocinero mayor de la reina.

Tenemos una detallada relación del guardamangier, encargado de la despensa de la reina, en la que informaba de los productos que solían proveerse para elaborar los platos de la reina. Se hace mención del consumo de aves como pollo, pichón y perdiz. Al mismo tiempo, era menos habitual la elaboración de platos con ternera y cabrito, y también pescado cuando era época. AGP, Administración General, leg. 929.

26 AGP, Administración General, leg. 929.

27 AGP, Administración General, leg. 368.

28 AGP, Administración General, leg. 909.

29 AGP, Administración General, leg. 368.

$30 \quad$ AGP, Administración General, leg. 781. 
(Sgorbati Bosi, 2018, p. 63). Las empanadas eran muy habituales en las meriendas de la pareja real, especialmente cuando residía en los Sitios Reales. El ambiente bucólico que envolvía los palacios de Aranjuez o el Pardo invitaba a la organización de partidas de caza, paseos a caballo y meriendas campestres. La empanada era el plato estrella, tanto por su fácil elaboración como por su conservación prolongada.

Pero si algo encantaba a la joven reina eran los dulces, que comúnmente se servían en las meriendas diarias. De hecho, su consumo había aumentado desde su llegada a Madrid, y la permanencia del confitero francés Pedro Borre es también una prueba de ello. En repetidas ocasiones hasta la muerte de María Luisa en 1689, la Junta del Bureo constató «el gasto tan excesivo que se ocasiona en los dulces que se dan todas las tardes para la merienda de las señoras damas, y mayor cuando viene la Reina Madre Nuestra Señora» ${ }^{31}$. María Luisa había hecho aumentar la preparación de dulces, sobre todo cuando su suegra Mariana de Austria le hacía una visita, «y en correspondencia de lo que en su Real Casa agasajan a las damas con dulces de Génova y muchos géneros de bebidas muy costosas» ${ }^{32}$. La confitería española, confirma Simón Palmer, «reúne la herencia árabe y hebrea y la funde con innovaciones que los cocineros aportan de sus países respectivos» (Simón Palmer, 1997a, p. 53). De hecho, el confitero de la reina debió de plasmar en sus postres todo el gusto francés que había traído consigo de los palacios del Rey Sol. Precisamente, lo que tanto demandaba María Luisa.

Esta rutina diaria en la mesa de la reina no era ninguna novedad. Pese a que en María Luisa primaban los gustos franceses, y que se afanaba en conservar a los cocineros que habían venido con ella desde París, otras consortes como Isabel de Borbón también habían mantenido dichas preferencias en sus cocinas. La verdadera novedad era, más bien, la relación que mantenía la pareja real. Desde su llegada a Madrid, María Luisa de Orleans había roto de bruces con la tradición. Los reyes pasaban todo el tiempo posible juntos, lo que incluía también sus comidas y cenas. Entre ellos había nacido una especie de idilio adolescente que tenía fascinada a toda la Corte (Contreras, 2003, p. 200). Porque no era común que un rey se enamorara de su consorte, o por lo menos nunca hasta los niveles de Carlos II. Antes de que ambos cónyuges se encontrasen en Burgos, María Luisa le había enviado un reloj y una corbata como regalo de cumpleaños. Desde entonces, «el Rey se pone [cada] mañana la corbata, y al reloj le dio cuerda y queda a su cabecera, y yo creo que sin el recuerdo del ruido que hace, se acuerda S.M. de que es novio» ${ }^{33}$. Una vez se conocieron, y pese al pobre español que

AGP, Administración General, leg. 929.

AGP, Administración General, leg. 880.

Archivo Histórico Nacional sección Nobleza (en adelante AHNobleza), Osuna, CT.19, D.17, Cartas del conde de Saltes y marqués de Fuentes a su sobrino [Gregorio de Silva Mendoza, V] duque de Pastrana [y futuro IX duque del Infantado] contándole la jornada real de Carlos II a Burgos para esperar a su esposa. 
hablaba la reina, los recién casados pasaban todo el tiempo que podían en compañía. Solían salir a pasear, disfrutaban de la celebración de comedias - que con María Luisa se volvieron todavía más recurrentes que en los reinados anteriores- y comían y cenaban juntos. Esto trastocaba el servicio de la vianda de las respectivas casas de los reyes. Pero trastocaba todavía más los intereses del nuevo valido.

Tras la muerte del príncipe bastardo Juan José de Austria, que ejerció despóticamente el puesto de primer ministro desde su asalto al poder en 1677, Carlos II había asumido el gobierno personal de la Monarquía. Sin embargo, nadie se engañaba demasiado, porque todo anunciaba que pronto se apoyaría en otros para gobernar. De hecho, a principios de 1680 se barajaban ya algunos nombres. Y el que más se escuchaba era el de su sumiller de corps, y también uno de los grandes de España con mayor influencia política: el duque de Medinaceli ${ }^{34}$. Su cercanía personal en la vida diaria del rey y sus habilidades a la hora de maniobrar entre don Juan y la reina madre le ofrecían algunos de los ingredientes necesarios para asumir el puesto de ministrofavorito (García Pérez, 2019, p. 159).

Desde febrero de 1680, Medinaceli comenzó a imitar a los validos de los reinados anteriores. En primer lugar, asumió en sus espaldas las tareas de gobierno. Los Consejos orbitaban a su alrededor y las principales cuestiones políticas pasaban primeramente por sus manos. A continuación, fue acumulando cargos y mercedes, siempre con las miras puestas a estar lo más cerca posible de Carlos II (Álamo Martell, 2004, p. 548). Pero había un factor que desestabilizaba el monopolio de Medinaceli, y ese era, precisamente, la reina consorte. El privado recelaba de la influencia que ella podía ejercer en su marido. Aunque algunos embajadores, incluido el nuncio apostólico, constataban que «la Regina sposa non pari che abbia messe le mani nel governo» ${ }^{35}$, había pequeños indicios que decían lo contrario. En primer lugar, porque María Luisa estaba ya recompensando a todos sus allegados, y el rey le daba siempre su beneplácito (Echavarren, 2015, p. 131). Al mismo tiempo, las comidas y cenas que la pareja real compartía suponían momentos de verdadera intimidad, en los que también podían tratarse temas políticos. Y eso, en un momento en el que volvían a respirarse nuevas tensiones entre Francia y España, empezó a inquietar a Medinaceli y su círculo.

Las paces de Nimega no habían frenado las ansias expansionistas de Luis XIV. En 1680, el marqués de la Fuente, embajador español en París, enviaba una carta cifrada a Madrid avisando de las intenciones del rey Cristianísimo: «no hay que hacer funda-

$34 \quad$ Fue nombrado primer ministro de Carlos II el 21 de febrero de 1680, con el objetivo de, en palabras del propio rey, «encargarte me ayudes en esta forma así por tus grandes obligaciones como por lo que en ti he experimentado», Archivo Ducal de Medinaceli (en adelante ADM), Archivo Histórico, leg. 45 , r. 21.

35 Archivio Segreto Vaticano (en adelante ASV), Segreteria di Stato, Spagna, sig. 155, fol. 118 v. 
mento sobre las expresiones con que me respondió el Rey tocantes a la manutención de la Paz, aunque fueron muchas ${ }^{36}$. En toda Europa se miraba con recelo cualquier movimiento francés. Y, en efecto, un año después de la llegada de María Luisa de Orleans, su tío planificó nuevamente la invasión de los Países Bajos. El embajador español en Holanda advertía de que se avecinaba un ataque inminente, «pues no se trata menos que de abandonar el País Bajo o de entrar en una guerra sin haber en Flandes nada de tanto como se requiere para emprenderla» ${ }^{37}$. Durante todo el bienio de 1681 y 1682 , la amenaza de la guerra revoloteó continuamente alrededor del Real Alcázar de Madrid. Las noticias llegaban de todos los territorios de la Monarquía, muchas veces inconexas y distorsionadas, otras estremecedoramente descriptivas, pero siempre coincidiendo en una misma idea: que Luis XIV, pese a sus evasivas, tenía intención de apoderarse de Flandes. Fue precisamente en este contexto, en el que empezó a extenderse un verdadero odio antifrancés, cuando se programaron importantes reformas en la Casa de la Reina y, por supuesto, también en sus reales cocinas.

El primer foco de amenaza estaba en la influencia que el marqués de Villars, embajador francés, y su esposa ejercían en la joven reina (Maura, 1997, p. 285). A parte del tiempo que disfrutaba con el rey, María Luisa se atrincheraba cada vez más alrededor de sus afectos, entre los que se incluían el embajador, la Cantina y otras camaristas francesas como Marguerite Duperroy. Las tensiones con Francia despertaron los recelos del primer ministro, que empezó a intrigar para desestabilizar lo que parecía convertirse en un verdadero partido francés. De modo que Medinaceli implantó un programa reformista que afectaba de lleno al círculo de la reina consorte. Primero convenció a Carlos II de la nociva influencia que Villars y su esposa ejercían sobre ella. La propia marquesa de Villars estaba convencida de que todo había sido una maniobra de Medinaceli, pues «si le premier ministre a fait négotier notre retour en France par l'ambassadeur d'Espagne qui est à Paris, le roi leur maître n'en a rien sçu; car le jour qu'on en eut ici la nouvelle, il parut fort étonné quand on la lui apprit» (Gigault de Bellefonds de Villars, 1868, p. 168). Con Villars expulsado de la Corte, el duque de Medinaceli dio un paso más allá. Aprovechando que María Luisa había caído enferma en cama por unas fiebres, solicitó al confesor real que le ayudase a convencer al rey para que recuperase la etiqueta establecida por Felipe IV. Lo que pretendía Medinaceli era aislar a Carlos II de otras influencias que no fuesen la suya, porque dicha etiqueta pautaba que los reyes hiciesen vida separada, «così nel mangiar pubblicamente separato dalla Regina, come nel dar le udienze nell'assistere al dispaccio, e nel far tenere

Archivo General de Simancas (en adelante AGS), Estado-K, leg. 1637, s/f.

AHN, Estado, libro 180, Correspondencia del embajador de Venecia, marqués de Villagarcía, con el embajador de Holanda, marqués de Castelrodrigo, (1677-1684). 
alla sua presenza il Consiglio di Stato ${ }^{38}$. A partir de entonces, la pareja real comería y cenaría en sus respectivos espacios, como así había sido con Felipe IV y sus consortes. Pero aquello no terminaba ahí, porque el valido continuó con su batería de reformas, esta vez focalizadas en la Casa de la Reina y destinadas a «excusar los gastos en todo lo posible, reduciéndolos o solo los precisos e indispensables y así he resuelto que los que no fueren de este género se reformen ${ }^{39}$.

La Junta del Bureo de la Reina, tribunal de justicia con jurisdicción sobre toda la servidumbre real, se puso manos a la obra, empezando por reunirse dos veces por semana (Benito, 1994, pp. 49-124). En lo que afectaba a las reales cocinas, el Bureo recuperó las reformas implantadas por Felipe IV en 1639 y presentó, a continuación, una relación de los criados que integraban los llamados «oficios de boca». De cara a este estudio, interesan los que trabajaban en las cocinas. El Bureo consideraba que «de los criados que pueden quedar en la cocina es su sentir sean el despensero, dos cocineros, cinco ayudas — que el uno ha de servir de pastelero-, los dos portadores que hay, cinco mozos de oficio, dos porteros, el busier, aguador y lechero» ${ }^{40}$. El problema era que había cuatro cocineros mayores: los españoles Juan Francisco Francisco y Francisco Vilón por un lado; y los franceses Carlos Collard y Lázaro Andrés por el otro. Por el momento, el Bureo no se atrevió a proponer al rey cuales eran los dos cocineros que debían quedar fuera de la plantilla, aunque no se debe ser demasiado perspicaz para imaginarlo, porque la Corte se estaba purgando ya de toda influencia francesa. No fue hasta principios de 1682 cuando la Junta del Bureo propuso por primera vez el despido de los cocineros franceses de la reina.

Mientras la familia real iniciaba el nuevo año asistiendo a las ceremonias religiosas programadas, se escuchaban rumores de movimientos de tropas en el norte. En la Cataluña pirenaica y en Fuenterrabía se estaban haciendo ya algunos preparativos militares por el miedo cada vez más real de que Luis XIV rompiese las hostilidades con España. El 24 de febrero de 1682 volvió a reunirse la Junta del Bureo para tratar la evolución de las reformas de la Casa de la Reina. En esta ocasión, se propuso el despido de los cocineros Collard y Andrés, aunque los miembros del Bureo reconocían también que no se atrevían «a dar dictamen a V.M. por habérseles hecho estas mercedes a contemplación de la Reina Nuestra Señora y gustar de que la sirvan, y así lo deja a su real arbitrio y soberanía $\rangle^{41}$. En cuanto a Pedro Borre, estaban de acuerdo en mantenerle en plantilla, pues solo él ejercía la función de confitero. Sin embargo, Carlos II no quiso contrariar a su amada esposa. A su parecer, lo más correcto era que

ASV, Segreteria di Stato, Spagna, sig. 157, fol. 1312.

AGP, Administración General, leg. 929.

Ibidem.

Ibidem. 
«estas plazas se vayan consumiendo como fueren vacando, [...] hasta que el número de todas quede igual al que tienen las de los oficios de mi Casa» ${ }^{42}$. La cuestión del personal francés de la reina quedaba, de ese modo, todavía pendiente.

El poder de Medinaceli y su influencia sobre el rey siguieron aumentando, mientras el peligro de una nueva guerra ensombrecía el idilio entre los reyes. En 1683, el duque era oficialmente el hombre más poderoso por detrás de Carlos. En mayo de ese año, este ordenó que, durante su residencia en Aranjuez, todos los asuntos pasasen primero por las manos de su valido, para que él decidiese qué merecía la atención regia. Esta medida fue interpretada, en palabras del nuncio, como un medio de «guadagnar il Privato il vantaggio d'esser il primo informato di tutti i negozi per trattargli a suo benefizio con derogazione dell'autorità e decoro Reale» ${ }^{43}$. Junto a esto, ese año el Almirante de Castilla dimitió como caballerizo mayor del rey y Medinaceli aprovechó la oportunidad para hacerse con el puesto.

En julio de 1683, el Bureo de la reina se reunía una vez más para analizar la evolución de la reforma de sus criados (Luzzi Traficante, 2014, p. 133). Carlos II había ordenado que conforme fuesen vacando plazas, estas ya no se cubriesen, hasta llegar, por fin, a la planta fijada por Felipe IV en 1639. Pero los miembros del Bureo no se conformaban con esto. De hecho, volvieron a plantear el problema de los criados franceses. Había un interés real por parte del mayordomo mayor, seguramente auspiciado por el propio favorito del rey, de purgar la Casa de la reina de influencias francesas. Todo fue inútil, porque Carlos insistía en lo anterior: «consérvense los criados franceses, ahorrándose de los españoles que no sirven; y acomodando a estos en otros empleos, pero sin echarlos hasta que se les ocupe» ${ }^{44}$. Esta fue la última vez que la Junta del Bureo planteó la cuestión del servicio francés de la reina.

Durante meses llegaron noticias sobre el imparable avance de las tropas francesas sobre los Países Bajos españoles. La violencia con la que actuaba aquel ejército sembraba el terror en los territorios del Norte: «son más horrorosos los avisos que llegan de los incendios y vejaciones con que franceses molestan inhumanamente todo el País Bajo» ${ }^{45}$. Se hablaba de aldeas y pueblos arrasados a cenizas. Luxemburgo había sido invadido, «echando de los lugares en que estaban acuartelados a los soldados, obligando con las amenazas y la fuerza [...] a hacerles juramento de fidelidad además de repartir el alojamiento de sus tropas en el País» ${ }^{46}$. Al mismo tiempo, la frontera pi-

Ibidem.

ASV, Segreteria di Stato, Spagna, sig. 160, fol. 450.

AGP, Administración General, leg. 929.

AHN, Estado, libro 182, Correspondencia del embajador de Venecia, marqués de Villagarcía, con el embajador de Holanda, marqués de Castelrodrigo, (1677-1684).

$46 \quad$ ASV, Segreteria di Stato, Spagna, sig. 157, fol. 1124 v. 
renaica se preparaba también para la movilización general ante una posible invasión. Carlos II había dado órdenes al Consejo de Aragón a finales de ese año para que «se hallen prontos los tercios de la Diputación, ciudad de Barcelona y Reino de Valencia, y esté en Cataluña a principios de abril que viene» ${ }^{47}$. Finalmente, en diciembre de 1683 España le declaró la guerra a Francia. Madrid se veía contagiado de un espíritu belicista, pero sobre todo de un odio antifrancés que venía respirándose desde meses atrás. Del mismo modo que en épocas anteriores, todo lo relacionado con Francia adquirió tintes verdaderamente negativos.

Como era inevitable, empezaron las represalias contra vasallos de Luis XIV residentes en la península. El Consejo de Aragón envió órdenes a los respectivos virreyes para que «pasasen provisionalmente al embargo de las haciendas de franceses» ${ }^{48}$. Además, ese mismo mes de diciembre se produjeron algunos despidos de franceses en el Real Alcázar ${ }^{49}$. En este caso, sabemos que los cocineros Collard y Andrés continuaron trabajando en las cocinas de la reina, aunque pueden imaginarse las tensiones que se respiraban en ellas. En cuanto a María Luisa de Orleans, se veía, de pronto, aislada. No había cumplido su deber de concebir un heredero y su imagen pública caía en un desprestigio que se transformaba incluso en odio. El propio Carlos II era el primero en castigar a su esposa conforme la guerra con Francia se recrudecía y el poderío español se hundía frente a los ejércitos del Rey Sol (Maura, 1990, p. 287). Así que la reina desfogó su frustración directamente contra Medinaceli. Primero se atrincheró en su círculo de afines, esa especie de partido francés que, pese a todo, seguía activo «per il rigori delle riforme meditate dal sr. Duca di Medinaceli»» $»^{50}$. A continuación, negó al valido que le hiciese las visitas diarias de cortesía a su antecámara. Se había terminado de abrir un cisma entre la reina y el ministro-favorito de Carlos II.

\section{El triunfo de la reina francesa: las cocinas de Palacio bajo la órbita de París}

A mediados de 1684 se anunciaba ya la necesidad de detener las hostilidades entre ambas Coronas. La política beligerante de Luis XIV se había cobrado un precio demasiado alto, incluso para alguien como él. Su despiadado ataque paralelo a los

Arxiu de la Corona d'Aragó (en adelante ACA), Consejo de Aragón, leg. 570, s/f.

ACA, Consejo de Aragón, leg. 76, s/f.

Contamos con antecedentes muy similares. Por ejemplo, cuando estalló la Guerra de Devolución durante la regencia de Mariana de Austria, se dio orden al contralor de la reina de «que hiciese quitar los panaderos franceses que están en la panadería de boca y se busquen otros que sirvan este ministerio». AGP, Administración General, leg. 652. 
Países Bajos españoles y a las fronteras del Sacro Imperio se estaba traduciendo en toda una quimera. Así que, en el verano de ese año, se iniciaron reuniones a fin de llegar a un acuerdo. En agosto se firmaba finalmente el tratado de Ratisbona, que establecía una tregua de veinte años (Salinas, 1988, p. 370). Los términos no fueron, ni de lejos, los más deseados para los españoles. Si Nimega se había convertido en una paz deshonrosa, Ratisbona no iba a cobrarse un precio menos alto. En una reunión del Consejo de Estado, se lamentaban de «no haberse podido mejorar las condiciones, ni vencerse la dificultad de las contribuciones en Flandes $\rangle^{51}$. España cedía la plaza de Luxemburgo y eso repercutía directamente en el mismo corazón del gobierno de Medinaceli. La confianza de Carlos II en su valido había ido decreciendo conforme avanzaba aquella guerra. De hecho, Ratisbona confirmó que se había abierto un cisma entre el rey y su favorito, lo que repercutió positivamente en la situación personal de la pareja real. Carlos y María Luisa reaparecían felices y juntos en público. Las tensiones que habían marcado su matrimonio durante los dos años anteriores parecían haberse esfumado de golpe.

En octubre de 1684, Carlos Collard, uno de los dos cocineros franceses de la reina, suplicó al marqués de Astorga que se le permitiera regresar a Francia ${ }^{52}$. En apariencia su baja no resultaba ningún contratiempo, sino todo lo contrario. El mayordomo mayor había reiterado una y otra vez que únicamente eran suficientes dos cocineros mayores. Sin embargo, París ya había enviado a Gil Forni, que empezó a asistir a Collard en sus funciones durante las semanas previas a su partida. María Luisa dio órdenes al marqués de Astorga de que «le jure y se le haga el asiento de tal cocinero mayor en lugar del ausente, dándole el goce que le pertenece, por haber experimentado que en el ejercicio acude a lo que es de su real gusto ${ }^{53}$. De hecho, Forni iba a consolidar unas dinámicas que se mantendrían intactas hasta la misma muerte de María Luisa de Orleans. Cada vez que un cocinero francés moría, como ocurrió en varias ocasiones hasta 1689 , era sistemáticamente sustituido por otro compatriota. De tal modo que las cocinas de la reina estuvieron dominadas siempre por franceses.

Nada más ser nombrado cocinero mayor, Forni tuvo su primer contratiempo. Aunque se le habían asignado la plaza y los gajes disfrutados por su antecesor, se quejaba al grefier de la reina de que no se le había retribuido todo el tiempo que pasó ayudando a Collard en las cocinas. Aunque el grefier intentó explicarle que lo que estaba demandando no tenía ningún precedente, y que era totalmente inviable, el cocinero terminó dirigiéndose directamente al mayordomo mayor, «y debiera no haber

AHN, Estado, 2802, ex. 35, f. 1 v.

AGP, Administración General, leg. 878.

AGP, Personal, caja 2688, ex. 6, Expediente de Gil Forni, cocinero mayor de la reina. 
molestado a V. Exa., cuando sabe, se le dijo esto mismo, [...] pues no puede haberle dicho nadie se haya hecho otra cosa con ninguno, ni se puede hacer sin merced particular del Rey Nuestro Señor ${ }^{54}$. Además, el grefier añadía que, si no se le habían pagado los gajes con anterioridad a su nombramiento, «no fue hacerle molestia sino cumplir con las de su puesto y las reales órdenes que para en su oficio, que ha haber hecho otra cosa no hubiera cumplido con él ni con su conciencia» ${ }^{55}$.

Forni no fue la única incorporación en las cocinas. Poco tiempo después de ser ascendido a cocinero mayor, la Corte de París repitió las dinámicas anteriores. Si ya había enviado a Gil Forni para asistir a Carlos Collard, en enero de 1685 hizo lo mismo con Juan Frayer, «y que se le deje obrar en las viandas que hiciere de su orden o por sí o con uno de los cocineros mayores». María Luisa ordenó al mayordomo mayor que se le admitiese «sin asiento ni goce por ahora, hasta que S.M. se halle satisfecha de su habilidad y pueda solicitar con el Rey N. S. lo demás que fuere de su gusto y servicio ${ }^{56}$. Aunque Frayer entró en las cocinas de Palacio sin gajes asignados, su nombramiento reforzaba un poco más el monopolio francés. De hecho, antes de que se cumpliese un año de su entrada en las cocinas, Carlos II «fue servido hacer merced a Juan Frayer, de nación francés, de plaza de cocinero mayor de la Reina Nuestra Señora y con todo el goce que a ella corresponde» ${ }^{57}$. Cuando comenzaba 1686, había tres cocineros franceses, frente a los dos españoles.

Mientras se dirimían asuntos menores en las cocinas de Palacio, Medinaceli veía derrumbarse los pilares de su ministerio. Ya no contaba con el apoyo de nadie, incluida la reina madre y, por supuesto, la consorte. Las facciones de Palacio habían intrigado en su contra y ahora apoyaban a la nueva estrella en alza: el conde de Oropesa (Rodríguez Besné, 2004, p. 574). Más joven que Medinaceli, y gozando además de un gran atractivo personal, supo generar cierta fascinación en Carlos II, hasta el punto de que le nombró presidente del Consejo de Castilla «con total independencia del primer ministro, $[\ldots]$ y las demostraciones que me dicen quiso ejecutar de despedirse [Medinaceli] lo manifiestan así» ${ }^{58}$. En abril de 1685, el duque de Medinaceli presentaba su renuncia formal ante el rey, «creyendo firmemente que en el estado presente convenía así al servicio y acierto de V.M. en su gobierno y que mi retiro del manejo de los negocios facilitará a [...] la suma comprensión y santa intención de V.M.» ${ }^{59}$. A

\footnotetext{
Ibidem.

55 AGP, Libros y Registros, Registro 171, s/f.

56 AGP, Personal, caja 16927, ex. 31, Expediente de Juan Frayer, cocinero mayor de la reina.

$57 \quad$ AGP, Administración General, leg. 878.

58 AHN, Estado, libro 176, Correspondencia del embajador de Venecia, marqués de Villagarcía, y particulares de España, (1677-1685).

$59 \quad$ BNE, ms. 9928, f. $15 \mathrm{v}$.
} 
continuación, fue desterrado de la Corte (Maura, 1990, p. 310). Como informaba en una carta el duque de Gandía: «ya habrás visto corrida la cortina a los misterios de la Corte, y en su teatro concluida la jornada del primer papel, habiendo mandado salir para Cogolludo al Señor Duque de Medinaceli» ${ }^{60}$.

De hecho, la desaparición del primer ministro supuso el inicio de cambios importantes en Palacio. Y el primero de ellos fue que María Luisa de Orleans reforzó su ascendencia sobre Carlos II. Ni siquiera las peleas y trifulcas protagonizadas por su camarilla de franceses, que terminaron en 1685 con un escándalo que iba a trascender más allá del Real Alcázar, consiguieron mitigar el amor que el rey sentía por su esposa $^{61}$. Además, casualidad o no, la reina manifestó señales de embarazo en varios momentos en los que su situación se volvía delicada. Ese mismo año, coincidiendo con la desaparición de su amada Cantina y otros miembros de la Cámara, María Luisa anunció que tenía una falta. Como escribía el embajador español en Venecia: «de cuentos de Corte ya sabes el fin que tuvo el de los franceses, hase seguido el tener la Reina algunos días de falta y si se continua hasta mañana no se hará una comedia de grande aparato ${ }^{62}$. Aunque volvió a ser una falsa alarma, a María Luisa le sirvió para ganar tiempo y dejar que las aguas volviesen a su cauce.

Durante el año de 1686, el Bureo retomó las reformas que había iniciado antes de que estallase la guerra con Francia (Luzzi Traficante, 2014, p. 134). Por lo pronto, hizo una lista con la composición completa de la Casa de la Reina basándose en la concesión de gajes. Aquella monumental lista incluía también al personal de las cocinas. Curiosamente, en ella aparecían solo dos cocineros mayores: los españoles Juan Francisco Franco y Francisco Vilón ${ }^{63}$. Esto podría hacer pensar, a priori, que el flujo de cocineros franceses se había detenido, sobre todo tras los escándalos que habían protagonizado la Cantina y su círculo. Sin embargo, la realidad era muy distinta. Porque el nuevo favorito del rey, Oropesa, no tenía intención alguna de contrariar a

$60 \quad$ AHNob, Osuna, CT 100, D. 4.

${ }_{61}$ La influencia de la Cantina en la pequeña Corte de María Luisa fue siempre enorme. Sin embargo, los escándalos que protagonizó durante el primer lustro de la nueva reina en España fueron todavía mayores. En 1685, las envidias y tejemanejes entre los franceses que componían la Cámara de María Luisa se tradujeron en un escándalo que salpicó a la propia reina. Uno de los enemigos de la Cantina y también de su esposo lanzó el rumor de que esta había proporcionado abortivos a María Luisa con la intención de evitar un posible embarazo y garantizar la Corona a Luis XIV. A raíz de aquello, la Cantina, su esposo y otros camaristas fueron detenidos y torturados. Finalmente, Carlos II ordenó su expulsión de España, lo que vació la Corte de María Luisa de Orleans de importantes componentes franceses. (Echavarren, 2016, p. 326).

AGP, Administración General, leg. 929.

62 AHN, Estado, libro 177, Correspondencia del embajador de Venecia, marqués de Villargarcia, y particulares de España, (1685-1691).

63 AGP, Administración General, leg. 929. 
María Luisa de Orleans. Siendo consciente del papel que la consorte había jugado en la caída de Medinaceli, prefirió no asumir el rol de nuevo valido del rey. Manteniéndose oficialmente en su puesto de presidente del Consejo de Castilla, Oropesa mostró una actitud mucho más prudente, encaminada siempre a mantener el favor de las mujeres en la vida de Carlos II (Kamen, 1987, p. 587). Por lo tanto, es lógico pensar que el Bureo de la reina no volviese a contemplar el despido del personal francés. El hecho de que ese año solamente hubiese dos cocineros españoles en la lista se debe, simplemente, a que habían fallecido los cocineros mayores franceses.

El día 20 de agosto murió Gil Forti, cuando no llevaba ni dos años trabajando en las cocinas, y el 26 de ese mismo mes le siguió Lázaro Andrés, el cocinero enviado personalmente por el duque de Orleans para servir a su hija ${ }^{64}$. El resto de franceses que había en las cocinas no contaban con el título de cocineros. Juan Frayer servía como cocinero mayor, pero todo indica que no empezó a cobrar gajes hasta unos meses después de la confección de la lista, y por eso no aparece nombrado en ella. Por otro lado, tanto Pedro Borre, que seguía ejerciendo sus funciones de confitero, como Nicolás Rigo, que asistía a Andrés, aparecen sin ser propiamente mencionados como ayudas de cocina.

En este panorama, con la Junta del Bureo reasumiendo las reformas que se habían programado ya para el año de 1683 , tenía sentido que únicamente se mantuviera a los dos cocineros españoles en plantilla. A fin de cuentas, el objetivo prioritario de Carlos II era, y había sido siempre, el de «reducir toda la paga de las Casas Reales a dinero poniendo a este fin una pronta regular y fija asistencia» (Luzzi Traficante, 2014, p. 134). Pero María Luisa insistía en sus gustos y preferencias. A diferencia de su antecesora francesa, Isabel de Borbón, la hija del duque de Orleans jamás se aclimató a que fuesen cocineros españoles los que preparasen su menú diario. Por ese motivo, no tardaron en ser incorporados más cocineros franceses.

Directamente desde Francia llegó a Palacio Gaspar Rabufat, que juró su plaza tan solo una semana después de la muerte de Gil Forni. Cuando el grefier preguntó al mayordomo mayor si Rabufat debía disfrutar de los mismos privilegios que había gozado Forni, la respuesta de este, tras consultar a Carlos II, fue que «habiendo tenido Gil Forni goce de cocinero mayor, se le debe dar a Gaspar Rabufat, supuesto que este ha sido nombrado en lugar de aquel» ${ }^{65}$. Al mismo tiempo, se buscó un nuevo cocinero que ocupase la vacante dejada por la muerte de Lázaro Andrés. Y como era de esperar, el mayordomo mayor de la reina fijó sus ojos en el que había sido el asistente de Andrés desde el día en que este llegó de París. Nicolás Rigo, que llevaba trabajando en

$64 \quad$ AGP, Administración General, leg. 878.

65 AGP, Personal, caja 870, ex. 20, Expediente de Gaspar Rabufat, cocinero mayor de la reina. 
las cocinas de Palacio como ayuda desde 1680, fue nombrado cocinero mayor ${ }^{66}$. De ese modo, las cocinas de la reina volvían a contar con un número desproporcionado de cocineros. Cuando terminó el año de 1686 había cinco: los españoles Franco y Vilón; y tres franceses: Frayer, Rabufat y Rigo. Algo que no deja de sorprender, teniendo en cuenta que el Bureo continuaba implantando reformas para ahorrar el excesivo gasto que seguía experimentándose en las respectivas Casas Reales.

La situación personal de María Luisa de Orleans, pese a no conseguir el objetivo que se esperaba de ella, es decir, proporcionar un heredero al trono, estaba consolidada. La reina madre había aprendido a quererla, y ambas se profesaban un cariño sincero. Al mismo tiempo, Carlos II seguía amándola. Sin embargo, cuando la reina contaba con tan solo veintisiete años, cayó gravemente enferma (Maura, 1990, p. 338). Tras una leve mejoría, avisó a los médicos «quejándose mucho del estómago y aquella hora la empezó una cólica tan violenta que no pudo detener ningún alimento» ${ }^{67}$. El 12 de febrero de 1689 , fallecía a consecuencia de una peritonitis aguda ${ }^{68}$. Su muerte terminó con aquella década de influencia francesa que parecía afectar a todos los ámbitos de su casa, y en especial a sus cocinas. De hecho, las relaciones entre Francia y España, siempre tensas desde la tregua de Ratisbona, llegaron nuevamente a un punto muy peligroso tras la muerte de María Luisa. El embajador francés empezó a preparar su equipaje para abandonar la Corte y los rumores sobre una inminente ruptura de las hostilidades entre ambas Coronas se hicieron realidad durante los meses siguientes. El Consejo de Aragón había recibido noticias alarmantes sobre movimientos de tropas francesas en las fronteras del norte, lo que «puede recelarse el que V.M. resuelva haya rompimiento con la Corona de Francia, y que lo estilado en este caso es venir orden a los virreyes para que se haga escripción [sic] de bienes y represalia de los bienes de franceses ${ }^{69}$. Como era de esperar, el 15 de abril, tan solo tres meses después de la muerte de su sobrina, Luis XIV declaraba la guerra a España, «a cuyo efecto ordena y encarga Su Mag. a todos sus súbditos, vasallos y servidores, acometan a los españoles y les ha prohibido, y muy expresamente les prohíbe, tener en adelante con ellos ninguna comunicación, comercio ni inteligencia, pena de la vida» ${ }^{70}$.

AGP, Personal, caja 880, ex. 29, Expediente de Nicolás Rigo, cocinero mayor y pastelero de la reina. AGP, Reinados, Carlos II, caja 143, ex. 2.

La causa de su muerte fue motivo de discusión durante las semanas siguientes. En la Corte hubo quienes hablaron de que la reina había sido envenenada. De hecho, el embajador francés insistió en estar presente durante la autopsia que se le iba a realizar, algo que finalmente le fue denegado. Actualmente contamos con el informe que se generó, y que indica como principal causa de la muerte de la reina una peritonitis aguda, (De Vera Tassis y Villarroel, 1690).

ACA, Consejo de Aragón, leg. 557, 34, f. 3.

AHN, Estado, leg. 2787, ex. 21, s/f. 
Para cuando estalló la guerra, las cocinas de la reina habían sido ya depuradas de cualquier influencia francesa. Ahora que María Luisa había fallecido, y a la espera de que Carlos eligiese a una nueva princesa para desposarse, los principales súbditos que habían acompañado a la hija del duque de Orleans en 1679, y aquellos otros enviados desde París durante los años siguientes, fueron despedidos. El día 1 de marzo de 1689, los cocineros mayores Juan Frayer, Gaspar Rabufat y Nicolás Rigo, además del confitero Pedro Borre, recibieron orden de «que todos los criados franceses se volviesen a Francia» ${ }^{71}$. Juan Francisco Franco y Francisco Vilón, los cocineros españoles que llevaban sirviendo en las cocinas de Palacio desde el periodo de la regencia, continuaron en activo y trabajaron en las viandas de Mariana de Neoburgo, la nueva reina consorte. Sin embargo, este no fue el final de la presencia francesa. Porque algunos de aquellos cocineros tuvieron oportunidad de regresar a Madrid. Es el caso, por ejemplo, de Gaspar Rabufat, que retornó a España para servir a María Luisa Gabriela de Saboya ${ }^{72}$. De igual modo, Nicolás Rigo trabajó en las cocinas de Felipe V con el puesto de pastelero que, ahora sí, fue ya introducido oficialmente entre los miembros del personal de cocina ${ }^{73}$. A fin de cuentas, el reinado del primer Borbón impregnó la Corte de Madrid de una influencia francesa mucho más descarada, que nada tenía ya que ver con los desesperados intentos de María Luisa de Orleans por mantener vivo el recuerdo de lo que había abandonado en París.

\section{Conclusiones}

A lo largo de estas páginas, se ha intentado mostrar hasta qué punto estaban sometidas las cocinas de Palacio a los intereses de la alta política. Y, en el caso de las cocinas de María Luisa de Orleans, fue todavía más evidente. Porque, durante los diez años en los que fue reina consorte, el asunto de sus cocineros estuvo muy presente no solo para su mayordomo mayor y la Junta del Bureo, sino también para el mismísimo primer ministro Medinaceli y su sucesor indirecto en el valimiento, el conde de Oropesa. Este interés se debe a varias razones que ya han sido analizadas.

Es importante constatar que la Casa de María Luisa se vio impregnada de un poderoso componente profrancés. Durante su primer lustro como reina, la Cámara estuvo dominada por la Cantina y su círculo de afines, además de por los marqueses de Villars. Por supuesto, esta estela francesa afectaba de lleno a las cocinas de la reina. Entre 1679 y 1689 siempre hubo cocineros franceses. Collard, Andrés, Frayer, Rabufat,

AGP, Administración General, leg. 878.

AGP, Personal, caja 870, ex. 20, Expediente de Gaspar Rabufat, cocinero mayor de la reina.

AGP, Personal, caja 880, ex. 29, Expediente de Nicolás Rigo, cocinero y pastelero de la reina. 
Rigo y, por supuesto, también el confitero Borre, jugaron su papel en el servicio de Palacio. Todos ellos representaban la constante e incómoda sombra gala que envolvió a María Luisa de Orleans hasta su último suspiro. De hecho, su presencia evidencia varias cosas a tener en cuenta. En primer lugar, que la ascendencia de la reina sobre su esposo era mayor que la que tuvieron algunas de sus antecesoras. Desde su llegada al Real Alcázar, María Luisa vio satisfechas muchas de sus demandas, entre las que se incluía el deseo de que fuese siempre un francés el que supervisara su menú diario. El mayordomo mayor, pese a sus desesperados intentos para que la reina se fijase en los cocineros españoles, tuvo que plegarse a la realidad. Por lo tanto, el objetivo del Bureo por conseguir el despido de Collard y Andrés en 1683 no debe contemplarse desde un prisma puramente económico. No se trataba solo de ahorrar la concesión de gajes y mantener a dos cocineros en plantilla. Lo cierto es que había un trasfondo menos evidente, y era el de eliminar toda influencia francesa del círculo de la reina.

El duque de Medinaceli fue el primero en constatar el peligro que suponía la construcción de un verdadero partido francés. La Cantina o el marqués de Villars suponían peones potencialmente sospechosos, sobre todo en un momento en el que las tensiones entre Francia y España volvían a recrudecerse. Aunque los cocineros mayores no jugaban un papel importante en la composición de facciones palaciegas, esto no quiere decir que no se los mirase también con recelo. Primero, porque la sombra de una guerra llevaba también implícito un odio irracional contra todo elemento enemigo, y esto también incluía a los compatriotas franceses. De hecho, en los meses que siguieron a la ruptura de hostilidades entre ambas Coronas fueron expulsados de Palacio numerosos miembros franceses del personal de la reina. En segundo lugar, los criados españoles se sentían marginados y despreciados ante la actitud de su nueva reina, que se empecinaba en relegarles a un papel pasivo en la preparación de sus comidas. Y, finalmente, se daba la circunstancia de que los cocineros franceses tenían serios problemas para adaptarse a las dinámicas que se seguían en las cocinas de la reina, como era el hecho de negarse a trabajar al mismo nivel con los españoles. Collard y Andrés ejemplifican a la perfección esta actitud, al exigir que fuesen únicamente ayudas franceses los encargados de asistirles. Todo lo anterior explica mejor los intentos del marqués de Astorga, seguramente motivado por las aspiraciones de Medinaceli, de limitar el número de cocineros a los dos españoles.

Finalmente, una última conclusión a tener en cuenta es el verdadero peso que tuvo la Corte de París en las cocinas de María Luisa de Orleans. Como se viene diciendo, durante aquellos diez años, siempre hubo cocineros franceses. Y fue el cocinero Lázaro Andrés quien sentó un precedente. Aun cuando las cocinas de la reina contaban ya con Carlos Collard como cocinero mayor y Pedro Borre como confitero, el duque de Orleans le enviaba otro cocinero. Esto no solo hacía más inútil la presencia 
de los españoles Franco y Vilón, sino que, además, reforzaba el monopolio francés en las cocinas. Carlos II no dudó en admitirle plaza y concederle gajes simplemente para contentar a su esposa. Por lo tanto, la entrada en escena de Andrés sentó las bases para las futuras dinámicas que iba a seguir la Corte de París. Cada vez que un cocinero francés moría o tenía intención de regresar a Francia, había ya un sustituto preparado. Veamos el año de 1686, que, en muchos sentidos, resulta ilustrativo. Ese año habían muerto los cocineros Forni y Andrés. Realmente no hacía falta que fuesen sustituidos, pues se contaba ya con los españoles Franco y Vilón, y acababa de jurar su plaza el francés Frayer. Pero eso no significó nada. A Andrés le sustituyó Rigo, algo lógico si tenemos en cuenta que llevaba años asistiéndole como ayuda de cocinas. Además, París se ocupó también de que la plaza de Forni quedase cubierta por otro de sus compatriotas. Así es como llegó a Madrid Gaspar Rabufat, que fue integrado en las cocinas poco tiempo después.

Este predominio francés en las cocinas de la reina, que fue mucho más evidente que el que se vivió con Isabel de Valois o Isabel de Borbón, llegó a su fin en el mismo momento en el que murió la principal responsable de todo aquello. María Luisa de Orleans fallecía en febrero de 1689 y un mes más tarde Carlos II daba órdenes de que todos los franceses de las cocinas fuesen despedidos. Se demuestra así que la presencia de aquellos cocineros siempre había sido algo privativo de María Luisa, y que no se contemplaba en absoluto el hecho de que pudiesen seguir sirviendo para la llegada de la nueva consorte. Solo cuando se inició el reinado de Felipe V, la influencia francesa en las cocinas se convirtió ya en algo endémico. Sus largos años en el trono iban a testimoniar una constante presencia de franceses sirviendo sus comidas y las de sus respectivas consortes. 


\section{Bibliografía}

Álamo Martell, Ma Dolores (2004), «El VIII Duque de Medinaceli: primer ministro de Carlos II», en Escudero, José A. (coord.), Los válidos, Madrid, Dikinson S.L., pp. 547-572.

Barozzi, Nicolo \& Berchet, Guglielmo (1860), Relazioni degli stati europei. Lette al Senato dagli ambasciatori veneti. Serie II. Spagna, Venecia, Stampa Pietro Nakatovich.

Benito, Emilio de (1994), «La Real Junta del Bureo», Cuadernos de Historia del Derecho, 1, pp. 49-124.

Borgognoni, Ezequiel (2019), «La construcción de la imagen regia de María Luisa de Orleans», Studia Historica. Historia Moderna, 41/1, pp. 353-377. < https://doi. org/10.14201/shhmo2019411353377>.

Contreras, Jaime (2003), Carlos II el Hechizado. Poder y melancolía en la Corte del último Austria, Madrid, Temas de Hoy. Historia.

EchavarRen, Arturo (2015), «El caso de la Cantina. Un escándalo palaciego en el Madrid de Carlos II», Cuadernos de Historia Moderna, 40, pp. 125-152. <https:// doi.org/10.5209/rev_CHMO.2015.v40.49165>.

García BARranco, Margarita (2002), «La Casa de la Reina en tiempos de Isabel de Valois», Chronica Nova, 29, pp. 85-107.

GARCÍA PÉREz, Francisco José (2017), «La oratoria sagrada como arma política: los predicadores de Juan José de Austria», Obradoiro de Historia Moderna, 26, pp. 237-265. <http://dx.doi.org/10.15304/ohm.26.4314>.

GARcía PÉREz, Francisco José (2018), Juan Rodríguez Coronel: un predicador jesuita en la Corte de Carlos II, Madrid-Oporto, Sindéresis.

GARCÍA PÉREZ, Francisco José (2018), «La imagen del ministro-favorito en el púlpito regio durante el reinado de Carlos II», Tiempos Modernos, $37<$ http://www. tiemposmodernos.org/tm3/index.php/tm/article/view/4190/784>.

Gigault de Bellefonds de Villars, Marie (1868), Lettres de Madame de Villars à Madame de Coulanges (1679-1681), París, Imprimerie Henri Plon.

Kamen, Henry (1987), La España de Carlos II, Barcelona, Crítica.

Lobato, María Luisa (2007), «Miradas de mujer: María Luisa de Orleans, esposa de Carlos II, vista por la marquesa de Villars (1679-1689)», en Farré Vidal, Judith (ed.), Teatro y poder en la época de Carlos II. Fiestas en torno a reyes y virreyes, Universidad de Navarra, Madrid, pp. 13-44. <https://doi. org/10.31819/9783964560223-002>.

Maura, Duque de (1946), María Luisa de Orleans. Leyenda e historia, Madrid, Calleja. 
Maura, Duque de (1990), Vida y reinado de Carlos II, Madrid, Aguilar.

Martínez Millán, José (2016), «La Casa de Mariana de Austria durante su exilio en Toledo (1677-1679)», en Valladares, Rafael; Feliciano, Barrios; Sánchez Belén, Juan A. (coords.), En la Corte del Rey de España. Liber Amicorum en homenaje a Carlos Gómez-Centurión Jiménez (1958-2011), Madrid, Polifemo, pp. 307-333.

Novo Zaballos, José Rufino (2016), Las Casas Reales en tiempos de Carlos II: la Casa de la reina Mariana de Austria, Tesis Doctoral inédita, Madrid, Universidad Complutense.

Oliván SANTALIESTRA, Laura (2006), Mariana de Austria en la encrucijada política del siglo XVII, Tesis Doctoral inédita, Madrid, Universidad Complutense de Madrid.

PÉrez SAMPER, María Ángeles (2011), Mesas y cocinas en la España del siglo XVIII, Gijón, Trea.

PÉrez SAmper, María Ángeles (2014), «Los Oficios de Boca en la corte española de los Austrias», en Hortal Muñoz, José Eloy y Labrador Arroyo, Félix (dirs.), La Casa de Borgoña: la Casa del Rey de España, Leuven, Leuven University Press, pp. 337-370. <https://doi.org/10.2307/j.ctt9qdz6d.17>.

RoDRÍGUEZ BESNÉ, José Ramón (2004), «Crisis y quebrantamiento político del noveno conde de Oropesa», en Escudero, José A. (coord.), Los validos, Madrid, Dikinson S.L., pp. 573-582.

SALINAS, David (1988), «La diplomacia española a través de los embajadores en La Haya (1665-1700)», Bulletin Hispanique, 90, pp. 363-374. <https://doi. org/10.3406/hispa.1988.4648>.

Simon Palmer, María del Carmen (1982), La alimentación y sus circunstancias en el Real Alcázar de Madrid, Madrid, Instituto de Estudios Madrileños.

Simon PAlmer, María del Carmen (1997a), La cocina de Palacio (1561-1931), Madrid, Castalia.

Simon Palmer, María del Carmen (1997b), «Nota sobre la vida de las mujeres en el Real Alcázar», Cuadernos de Historia Moderna, 19, pp. 21-37.

Sgorbati Bosi, Francesca (2018), A la mesa con los reyes. La cocina en tiempos de Luis XIV y Luis XV, Barcelona, Gatopardo Ediciones.

Vera Tassis y Villarroel, Juan de (1690), Noticias historiales de la enfermedad, muerte y exsequias de la esclarecida reyna de las Españas Doña María Luisa de Orleans, Borbón Stuart y Austria [...] digníssima consorte del rey [...] Don Carlos Segundo de Austria, Madrid, Imprenta Francisco Pérez. 
